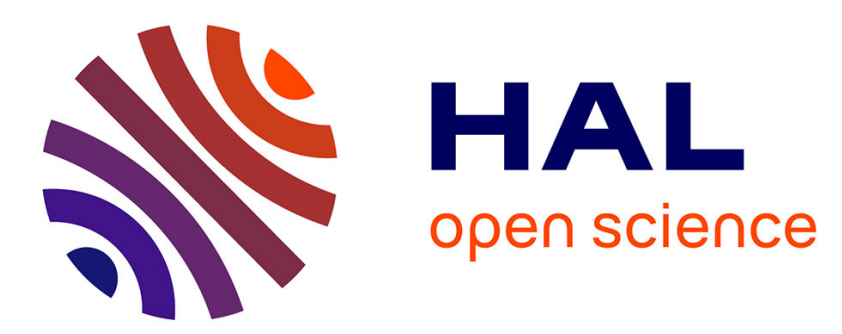

\title{
Modeling of the large deformation and the rupture of a metallic plate subjected to explosion
}

Benjamin Daudonnet, Frédéric Mercier, Krzysztof Woznica

\section{To cite this version:}

Benjamin Daudonnet, Frédéric Mercier, Krzysztof Woznica. Modeling of the large deformation and the rupture of a metallic plate subjected to explosion. ASME Pressure Vessels and Piping Conference 2008 (PVP2008), Jul 2008, Chicago, United States. pp.NC. ineris-00976210

HAL Id: ineris-00976210

https://hal-ineris.archives-ouvertes.fr/ineris-00976210

Submitted on 9 Apr 2014

HAL is a multi-disciplinary open access archive for the deposit and dissemination of scientific research documents, whether they are published or not. The documents may come from teaching and research institutions in France or abroad, or from public or private research centers.
L'archive ouverte pluridisciplinaire HAL, est destinée au dépôt et à la diffusion de documents scientifiques de niveau recherche, publiés ou non, émanant des établissements d'enseignement et de recherche français ou étrangers, des laboratoires publics ou privés. 


\section{MODELING OF THE LARGE DEFORMATION AND RUPTURE OF A METALLIC PLATE SUBJECTED TO EXPLOSIVE LOADING}

\author{
Benjamin Daudonnet / Baker Engineering and \\ Risk Consultants, 304-5515 N. Service Road \\ Burlington, Ontario, L7L 6G4 Canada
}

\author{
Frédéric Mercier / INERIS, Accidental Risk \\ Department, BP 2, Verneuil en Halatte, 60550, \\ France
}

\section{Krzysztof Woznica / ENSI de Bourges, Institut PRISME, Laboratoire Energétique Explosion Structures EA 1205, 88, bd Lahitolle, 18020 Bourges Cedex - France}

\section{ABSTRACT}

Thin walled metal pressure vessels or pipes commonly used in industry can burst under certain circumstances: as a result, the pressure envelope may undergo large deformations, which may eventually lead to a rupture. The response of these vessels to static and quasi-static loads is relatively well-understood but their response to highly dynamic pressure loading conditions is not.

This paper describes a numerical study of the response of circular metal plates to the dynamic loads produced by hydrogen-oxygen explosions. In this study, a range of dynamic responses and rupture criteria models are considered and compared with the results of experiments. The ability of MSC MARC software to model the rupture phase and, in some cases, the post-rupture phase (i.e., fragment production) is also discussed.

\section{NOMENCLATURE}

$\mathrm{a}=$ kinematic parameter, $\mathrm{Pa}$

$\mathrm{b}=$ isotropic parameter

$c=$ kinematic parameter

$\mathrm{D}=$ damage parameter

$\mathrm{E}=$ Young modulus, $\mathrm{Pa}$

$\overline{\mathrm{E}}=$ Young modulus modified by damage, $\mathrm{Pa}$

$\mathrm{J}=$ scalar equivalent of deviatoric stress state, $\mathrm{Pa}$

$\mathrm{K}=$ viscous parameter, $\mathrm{Pa}$

$\mathrm{k}=$ initial yield limit

$\mathbf{n}=$ viscous parameter

$\dot{\mathrm{p}}=$ accumulated inelastic strain rate, $\mathrm{s}^{-1}$

$\mathrm{R}=$ drag stress, $\mathrm{Pa}$
$\mathrm{R}_{1}=$ isotropic parameter, $\mathrm{Pa}$

$\mathbf{s}^{\prime}=$ deviator of stress tensor $\mathbf{s}, \mathrm{Pa}$

$\mathrm{T}=$ temperature, $\mathrm{K}$

$\mathbf{X}=$ back stress tensor, $\mathrm{Pa}$

$\mathbf{X}^{\prime}=$ deviator of back stress tensor $\mathbf{X}, \mathrm{Pa}$

$\alpha, \beta=$ parameters of damage law, $\mathrm{Pa}^{-1}$

$\varepsilon=$ strain

$\varepsilon_{\mathrm{f}}=$ limit of strain at rupture

$\dot{\varepsilon}=$ inelastic strain rate, $\mathrm{s}^{-1}$

$\dot{\boldsymbol{\varepsilon}}^{\mathrm{i}}=$ inelastic strain rate tensor, $\mathrm{s}^{-1}$

$\gamma=$ parameter of Chaboche law, $\mathrm{s}^{-1}$

$\bar{\sigma}=$ Von Mises equivalent stress, $\mathrm{Pa}$

$\sigma_{H}=$ hydrostatic stress, $\mathrm{Pa}$

$\sigma^{*}=$ stress triaxiality, $\mathrm{Pa}$

$\mathrm{Pi}=$ pressure at ignition, bar

\section{INTRODUCTION}

A wide range of vessel rupture models models are available in the open literature. Some models, (i.e., Qiu et al. [17], Recho [18], Su et al. [21]) rely on the mechanical aspects of the failure such as crack propagation, while other models (i.e., Haque et al. [7], Leung [12], Woodward and Mudan [23], Fthenakis et al. [6]) treat the failure using fluid mechanics. Few models are available that consider both aspects of the failure. Where they exist, most studies in this behaviour are focussed on pipeline rupture, (i.e., Iung [8], Emery [4] and Rivalin [19], [20]). 
In addition the modelling efforts listed, several experimental studies of structures subjected to a dynamic load have also been performed, for both simple ([5], [14], [15], [22], [16]) and complex structures ([1], [4]).

In this paper, experiments to measure the response of thin plates to various dynamic loads are presented. The experimental results illustrate the dynamic behavior and the rupture of the structure. These results were then compared to the results of a numerical model. The conclusions and the possible future use of the model are also presented.

\section{EXPERIMENTS}

\section{Experimental device}

The experimental device to test the metal plates, based on the one used in [24], is shown in Figure 1. Two stainless steel tubes were used: Tube 1 is $800 \mathrm{~mm}$ long and Tube 2 is $400 \mathrm{~mm}$ long. Each tube has an inside diameter of $194 \mathrm{~mm}$ and a wall thickness of $12.5 \mathrm{~mm}$. The metal plate to be tested is clamped between these two tubes. Some experiments were performed with a rounded edge between the tube and the plate, in order to prevent the circumferential rupture caused by the sharp edge.

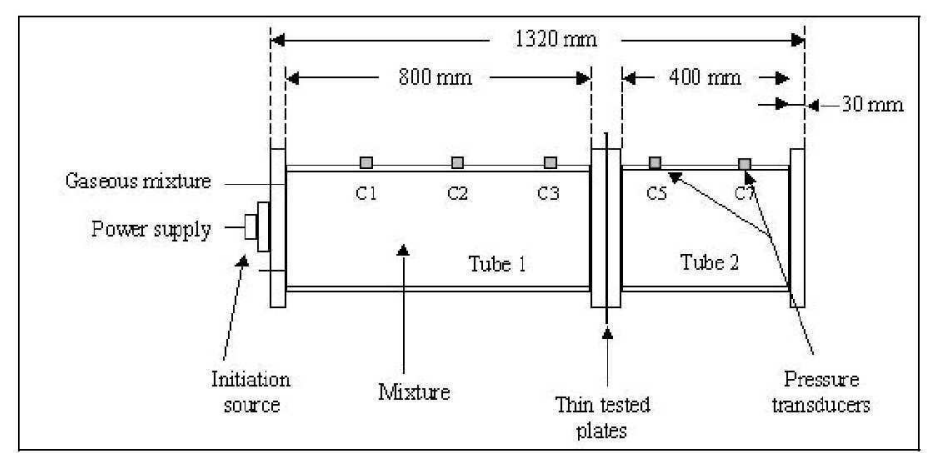

Figure 1: Experimental Device

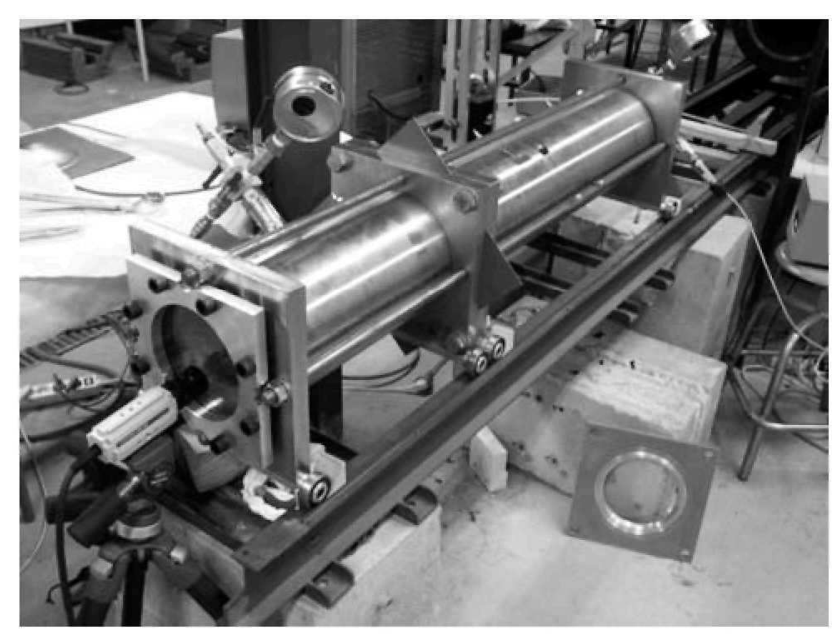

Photo 1: Photograph of the Experimental Device
Photo 1 displays the setup for the experiment. In addition to the elements already described above, a high speed camera (shown in the foreground) was used to record the crack propagation and pattern of the tested plates at 10000 frames/second.

The experiments were conducted as follows. Once the testing plate was clamped between the tubes, a vacuum was simultaneously created in Tubes 1 and 2. A stoichiometric hydrogen-oxygen mixture was then introduced in Tube 1, while air was fed into Tube 2, to balance the pressure across the plate. Two kinds of explosion could then be produced:

- a "deflagration", in which the mixture was ignited by a low energy discharge (mJ range), such as an electric spark, or

- a "detonation", in which the mixture was ignited by a stronger ignition energy ( $50 \mathrm{~J}$ in our experiment). In this case, the shock wave is supersonic and very stable, resulting in a very repeatable dynamic loading condition, whereas deflagration case produced a more stochastic load. When the shock wave reaches the tested plate, its velocity and overpressure peak are not those of a real detonation. For the purposes of discussion, the term "deflagration" also is used to refer to an explosion produced using the low energy ignition systems and the term "detonation" is used to describe the high ignition energy event, even though these terms are not exact for describing the two explosion modes.

A sample pressure trace from a detonation test is provided in Figure 2. The successive peaks represent the reflections of the wave inside the tube.

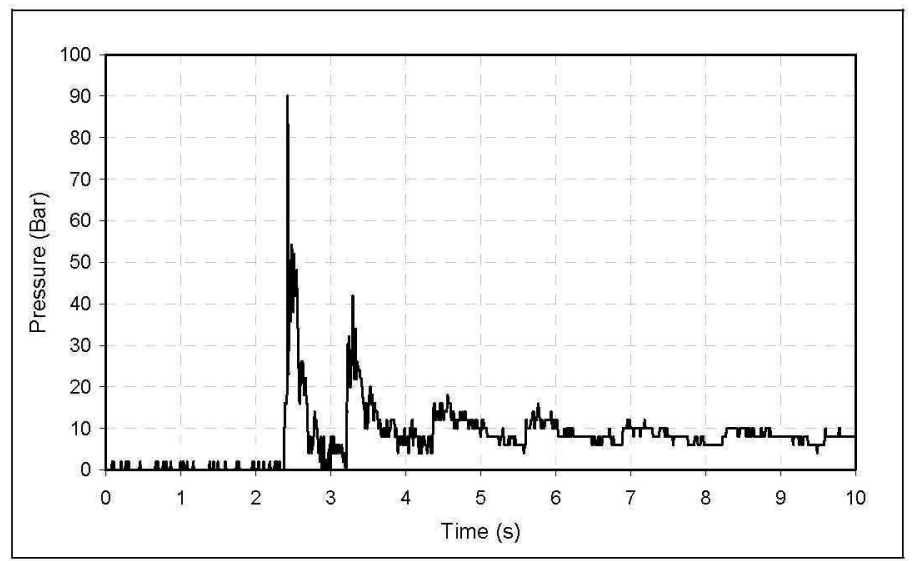

Figure 2: Pressure-Time History - Detonation-( $\mathrm{Pi}=1.2$ bar)

\section{Experimental results}

Different plate thicknesses $(2 \mathrm{~mm}, 1 \mathrm{~mm}$ and $0.5 \mathrm{~mm})$ and materials (A15754, A12017, DC01) were tested. With the sharp edge, the plates were either bulged or split along the edge. With the rounded edge, the plates were also bulged but larger deformations were observed (Photo 2), as higher loadings could be applied without resulting in a circumferential rupture. For the Al5754 $(1 \mathrm{~mm})$ plates with the rounded edge, caps of different size (Table 1) were ejected (Photo 3 ): the rupture was not a shear rupture, as observed with the sharp edge. 


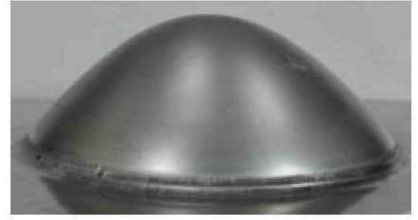

Photo 2: Bulged Plate (AL5754, Detonation, $\mathrm{Pi}=1.1$ bar, Rounded Edge)

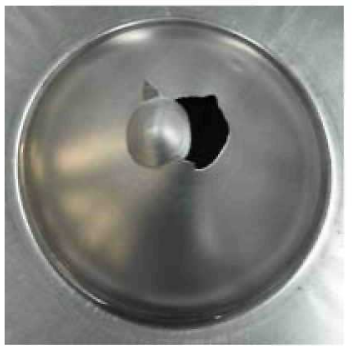

Photo 3: Cap Ejected (Al5754, Detonation, $\mathrm{Pi}=1.2$ bar, Rounded Edge)
Table 1: Diameter of Caps for Different Loads

\begin{tabular}{|l|l|l|l|}
\hline Initial pressure [bar] & 1.1 & 1.2 & 1.4 \\
\hline Cap diameter [mm] & 0 & 37 & 150 \\
\hline
\end{tabular}

Another way to initiate the rupture and control its starting location was to create a notch. Notches of different widths, from $0.3 \mathrm{~mm}$ to $1.6 \mathrm{~mm}$, were created in the center of the plate. Photo 4 is an example of the results obtained for a $1 \mathrm{~mm}$ Al5754 notched plate.

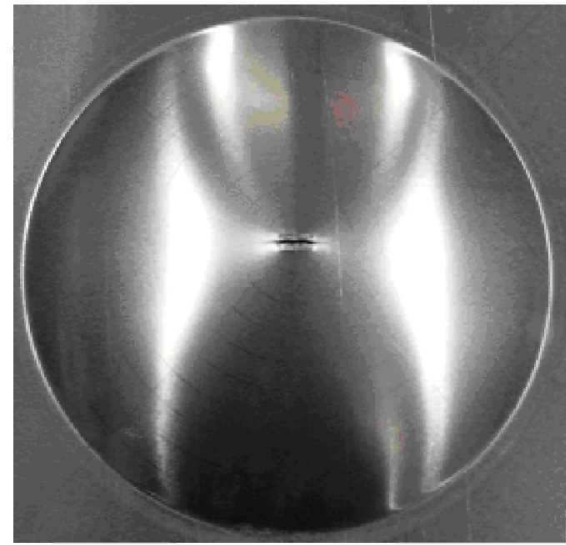

Photo 4: Experimental Result for Al5754 Notched Plate (Deflagration, $\mathrm{Pi}=0.8$ bar, Sharp edge)

\section{MODELING}

\section{Characteristics of the modeling}

The numerical modeling of the experiments was performed using the commercial software package MSC.MARC [13]. Since the plate thickness is much smaller than its radius, thin shell elements were used to create the plate model. In addition, one-dimensional axisymmetric shell elements were used in order to reduce processing times. The load function was defined using the pressure data recorded during the experiments: the pressure-time history was defined as a pressure force normal to the surface.

\section{Material behaviour - Chaboche model}

The elastoviscoplastic law of Chaboche [11] was chosen to describe the material behavior. It was demonstrated that this law gives accurate results, comparable to those obtained in experiments [24]. The relations introduced in this law are, for the inelastic strain rate $\dot{\boldsymbol{\varepsilon}}^{i}$ :

$$
\dot{\mathbf{\varepsilon}}^{\mathrm{i}}=\frac{3}{2} \dot{\mathrm{p}} \frac{\mathbf{s}^{\prime}-\mathbf{X}^{\prime}}{\mathrm{J}\left(\mathbf{s}^{\prime}-\mathbf{X}^{\prime}\right)}
$$

where $\dot{p}$ is the accumulated inelastic strain rate,

$$
\dot{\mathbf{p}}=\gamma\left\langle\frac{\mathrm{J}\left(\mathbf{s}^{\prime}-\mathbf{X}^{\prime}\right)-\mathrm{R}-\mathrm{k}}{\mathrm{K}}\right\rangle^{\mathrm{n}}
$$

$K$ and $n$ are viscous parameters, $\gamma=1\left[\mathrm{~s}^{-1}\right]$. The parameter $\mathrm{k}$ is the initial yield limit.

s' denotes the deviator of stress tensor $\mathbf{s}, J(\ldots)$ is the scalar equivalent of deviatoric stress invariant. $\mathrm{R}$ is a drag stress.

This law introduces an isotropic hardening:

$$
\dot{\mathrm{R}}=\mathrm{b}\left(\mathrm{R}_{1}-\mathrm{R}\right) \dot{\mathrm{p}}
$$

where $R_{1}$ and $b$ are material parameters.

A kinematic hardening is expressed through the evolution of the back stress $\mathbf{X}$,

$$
\dot{\mathbf{X}}=\frac{2}{3} \mathrm{a} \dot{\boldsymbol{\varepsilon}}^{\mathrm{i}}-\mathrm{cX} \dot{\mathrm{p}}
$$

where $a$ and $c$ are the law parameters.

The following material data, validated for $\mathrm{Al} 5457$ at $T=20^{\circ} \mathrm{C}$ (Woznica et al., [24]), were used in the Chaboche viscoplastic model:

$$
\begin{aligned}
& E=71.11 \mathrm{GPa}, \\
& n=8.9 ; \\
& k=101.64 \mathrm{MPa}, \\
& a=54049 \mathrm{GPa}, \\
& R_{1}=178.45 \mathrm{MPa} .
\end{aligned}
$$

$$
\begin{aligned}
& \gamma=1 \mathrm{~s}^{-1}, \\
& K=13.97 \mathrm{MPa}, \\
& c=2478.3, \\
& b=14.68,
\end{aligned}
$$

\section{Rupture criteria}

The damage model proposed by Chaboche and Lemaitre [11] is a fully coupled model. It is based on the damage parameter D which can be expressed as a ratio between the Young's Modulus modified by the damage and its initial value.

$$
\mathrm{D}=1-\frac{\overline{\mathrm{E}}}{\mathrm{E}}
$$

The value $D=0$ corresponds to a non-damaged state, while $\mathrm{D}=1$ corresponds to a fully damaged (i.e., failed) state.

$$
\dot{\mathrm{D}}=\left[\frac{\bar{\sigma}^{2}}{2 \mathrm{E} \alpha(1-\mathrm{D})^{2}} \mathbf{f}\right]^{\beta} \dot{\varepsilon}^{\mathrm{i}}
$$

where $f$ is a function of the stress triaxiality.

The parameters $\alpha$ and $\beta$ corresponding to this damage law are expressed in equation (6). They can be using tensile loading/unloading tests where, $f$ is a constant, [3]. 
While Chaboche was used as the basis for this study, other rupture criteria could also be used. To evaluate some of these alternatives, the following rupture criteria were also considered and defined into MSC Software:

- strain limit a simple strain limit obtained from tensile tests was used to define the rupture.

- strain rate:

Another limit, based on the strain rate was also defined [9]:

$$
\varepsilon_{\mathrm{f}}=\left[\mathrm{D}_{1}+\mathrm{D}_{2} \exp \left(\mathrm{D}_{3} \sigma^{*}\right)\right] \times\left[1+\mathrm{D}_{4} \ln (\dot{\varepsilon})\right] \times\left[1+\mathrm{D}_{5} \mathrm{~T}\right](7)
$$

where $\varepsilon_{\mathrm{f}}$ is the strain at rupture, $\sigma^{*}$ is the triaxiality and $\dot{\varepsilon}$ is the non-dimensional strain rate,

- triaxiality damage:

this criteria was used by Lee and Wierzbicky [10] for rupture of a thin plate under projectile loading as follows:

$\mathrm{D}_{\mathrm{c}}=\int_{0}^{\varepsilon_{\mathrm{f}}} \frac{\sigma_{\mathrm{H}}}{\bar{\sigma}} \mathrm{d} \varepsilon$

where $\sigma_{H}$ is the hydrostatic stress, and $\bar{\sigma}$ the Von Mises equivalent stress.

\section{RESULTS}

The numerical modeling and analysis were compared to the experimental results for both the ruptured and unruptured plate conditions.

\section{Tests with no rupture}

The MSC software model was validated by comparing the results obtained with those of Woznica et al. [24]. The close agreement between these results ([2]) indicates that the model is appropriate.

Additional comparisons to the experiments were then made:

- the final plate deflection along the radius was measured and compared to the numerically-predicted value at different times. As shown in Figure 3, good agreement between the numerical and the experimental results was observed.

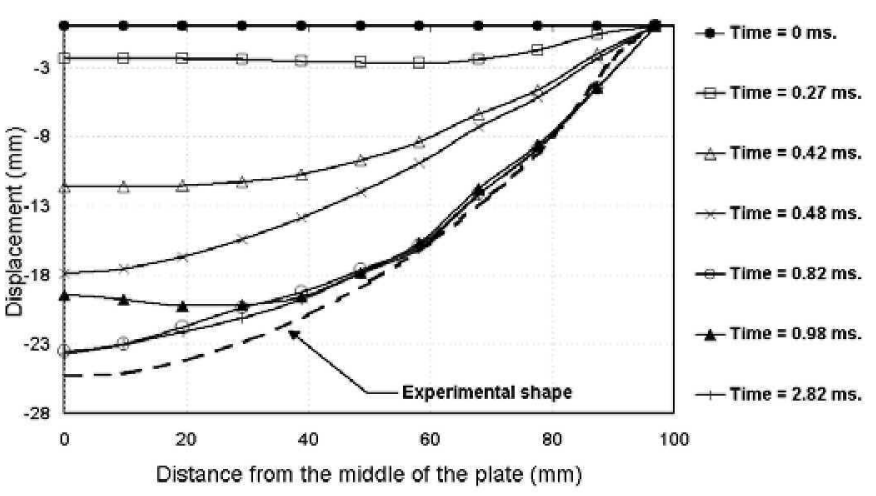

Figure 3: Plate Deflection at Different Times (Deflagration, $\mathrm{Pi}=0.8$ bar, Sharp Edge)

- the large displacement and deformation of the plate observed when introducing a rounded edge plate holder also showed good agreement with the numerical results (Figure 4).

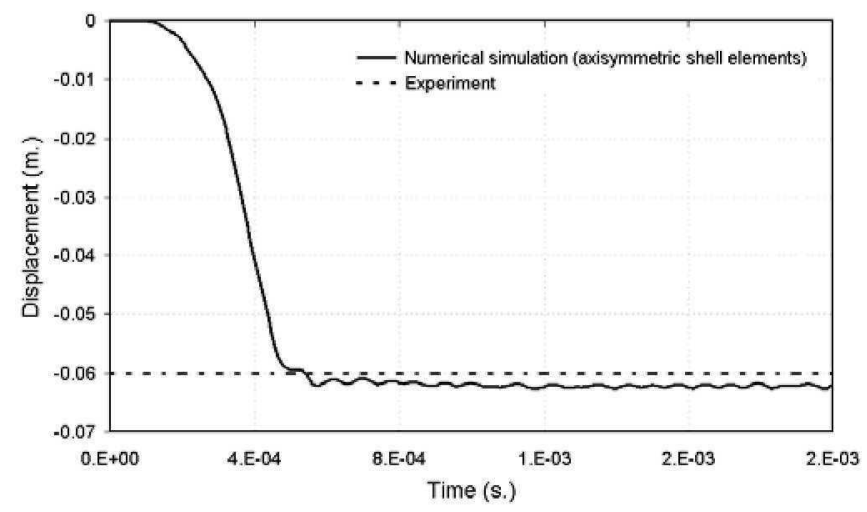

Figure 4: Numerical Displacement and Final Experimental Deflection at the Center of a Plate (Detonation, $\mathrm{Pi}=1.1$ bar, Rounded Edge)

Following the verification of the deformation model using the Chaboche law, modeling of the rupture case was then studied.

\section{Tests with rupture}

Three different rupture tests were studied: un-notched plate with the rounded edge, notched tensile test specimen, notched explosive test specimen.

\section{Un-notched Plate under Explosive Load}

The rupture that occurs at high loadings with the rounded edge was studied using axisymmetric shell elements. Comparing the results obtained using different rupture criteria (i.e, strain, strain rate, damage) we notice that the best results (see Table 2) were obtained for criteria that take into account the strain rate or the damage (i.e., Chaboche-Lemaitre). 
Table 2: Cap Radius Predictions

\begin{tabular}{|c|c|c|c|}
\hline & \multicolumn{2}{|c|}{ Cap radius (mm) } \\
\hline & & $\begin{array}{l}\text { Detonation } \\
\mathrm{Pi}=1.2 \text { bar }\end{array}$ & $\begin{array}{l}\text { Detonation } \\
\mathrm{Pi}=1.4 \text { bar }\end{array}$ \\
\hline \multicolumn{2}{|c|}{ Experimental Result } & 18.5 & 75 \\
\hline \multirow{4}{*}{ 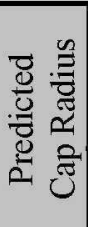 } & Strain & 39 & 59,52 \\
\hline & Strain Rate $(\dot{\varepsilon})$ & 24 & 56 \\
\hline & Triaxiality Damage & 52,5 & 62,6 \\
\hline & $\begin{array}{c}\text { Chaboche Lemaitre } \\
\text { Damage Model }\end{array}$ & 30 & 72 \\
\hline
\end{tabular}

These results illustrate the importance of the strain rate and the damage effect on the material response.

\section{Notched Tensile Test Specimen}

Before the studying of the failure of the notched plates under explosive loading, tensile test specimens were modelled. The aim of this experiment was to verify the adequacy of a method to model the rupture. We applied the strain criteria combined with the deletion of elements, as illustrated in Figure 5.

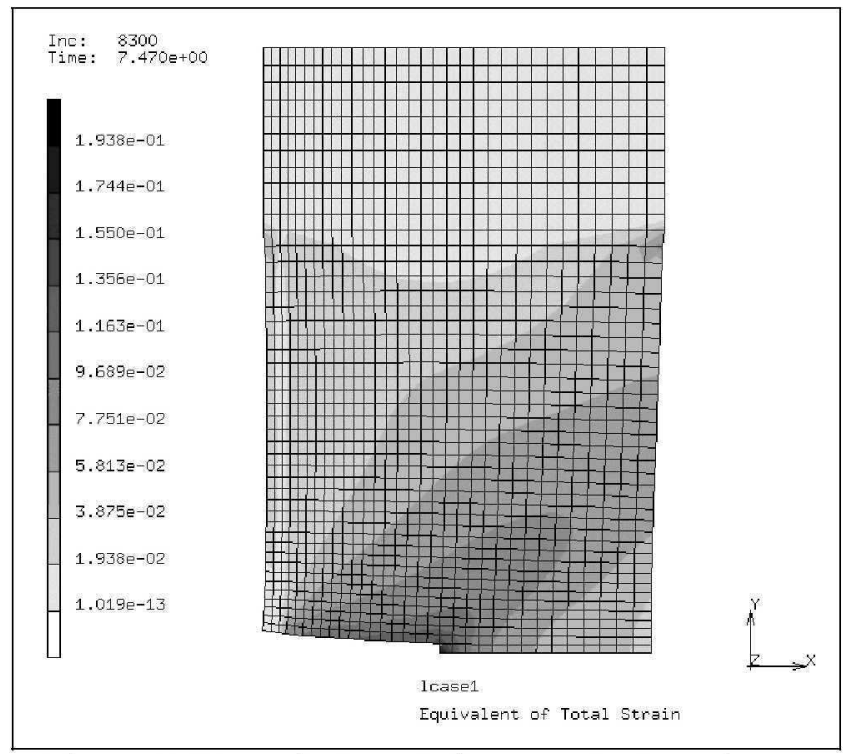

Figure 5: Numerical result for a notched specimen: Equivalent Total Strain

For A12017, the crack length and velocity measured were compared to the calculated results. As presented in Figure 6 and Figure 7, good agreements were obtained, relative to the complexity of the phenomenon. This method could be applied for more elaborate arrangement, but any such model must be applied carefully as it can be subject to variation (for example if the size of the element is too large).

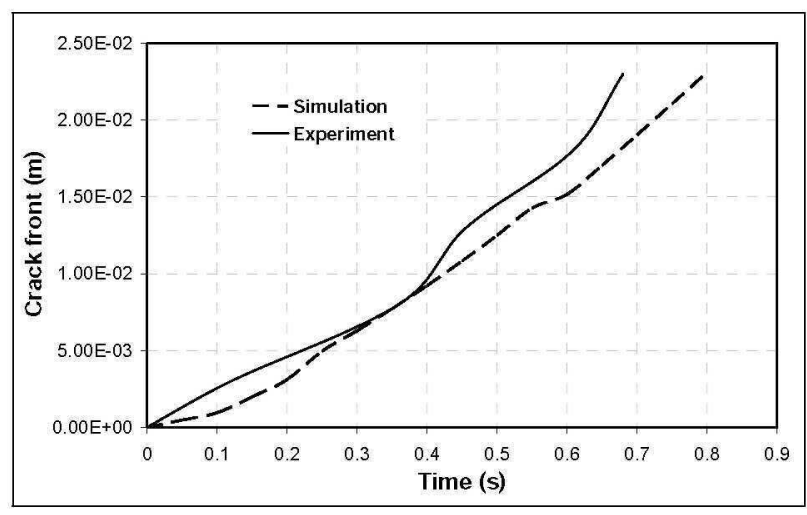

Figure 6 : Crack Length Evolution (Al2017)

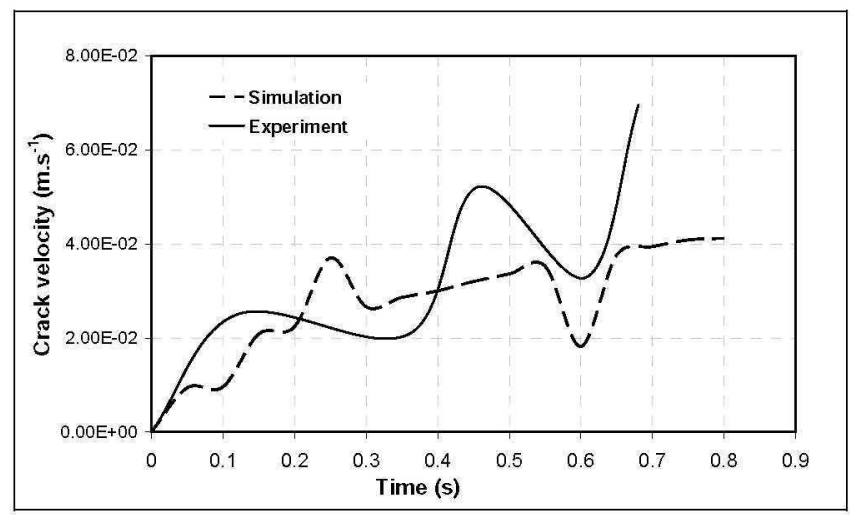

Figure 7 : Crack Velocity Evolution (Al2017)

\section{Notched Explosive Test Specimen}

As presented above, a notch was created in the center of the plate in order to initiate and control the location of the rupture. The result of this experiment can be observed in Photo 4 for A15754. Good results were obtained numerically, as shown in Figure 8 and Figure 9. The general shape of the crack predicted is very similar to that observed experimentally. The discontinuities observed in the crack velocity prediction are attributed to the discontinuities inherent to the modeling (i.e., the deletion of an element cannot be continuous). Once the abnormal values of crack velocity are excluded, the numerical result appears to be of the same order as the measured value (between 200 and $300 \mathrm{~m} / \mathrm{s}$ ). 


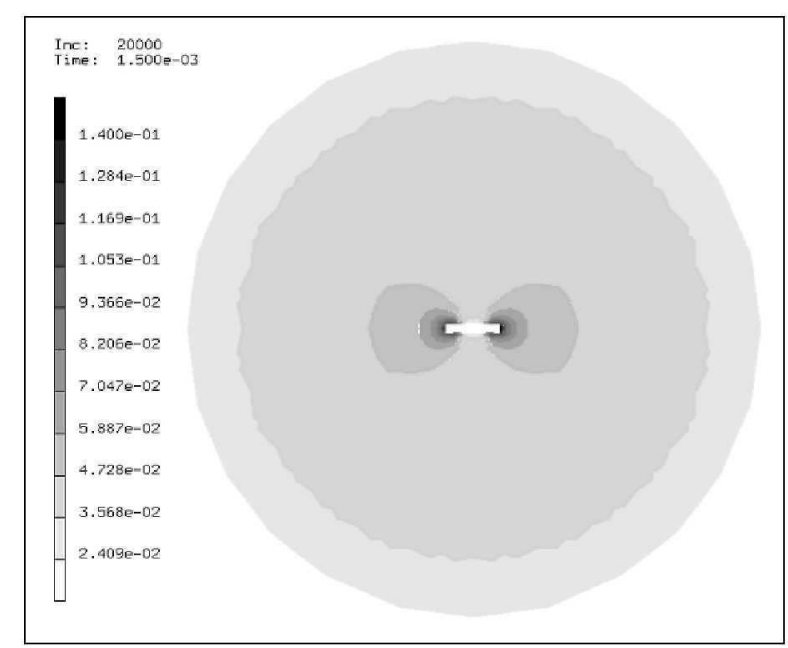

Figure 8: Numerical Result for Al5754 notched plate: Equivalent Total Strain (Deflagration - $\mathrm{Pi}=0.8$ bar)

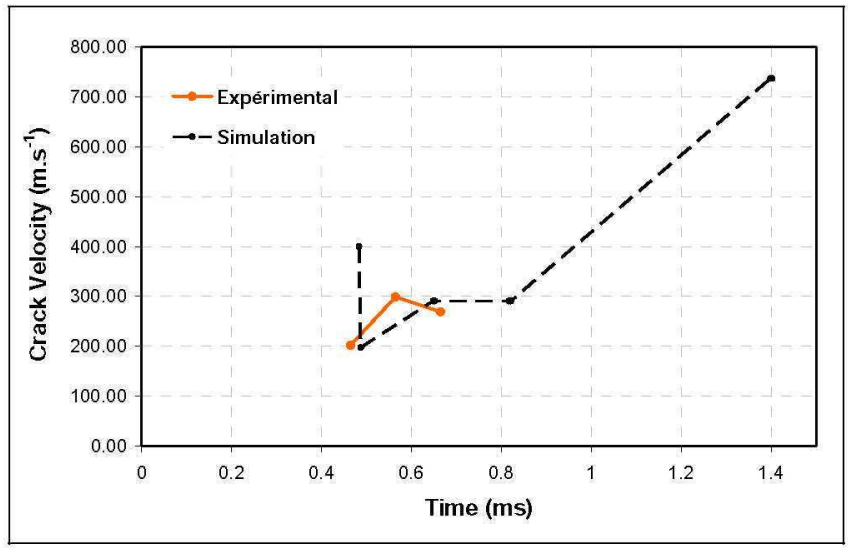

Figure 9 : Comparison of Crack Velocity

\section{CONCLUSION}

This paper compares experimental results to results obtained using numerical simulations for metallic plates subjected to explosive loads.

The numerical prediction used an axisymmetric model for a metallic plate subjected to a dynamic load. The material deformation was predicted using the Chaboche viscoplastic law, where the material characteristics have been identified from tensile tests. Accounting for the strain rate or the damage was shown to improve the accuracy of the prediction of the rupture (compared to a basic strain criterion). Combining such a criterion with the deletion of elements provides a good match to experimental data (shape, velocity) for this complex phenomenon. These results indicate that this method could be a viable means of studying rupture.

\section{RECOMMENDATIONS FOR FUTURE WORK}

While this study has shown good agreement for thin plates in a fixed geometry, a more detailed analysis of the limits of validity of this method is recommended. Another extension of this work would be to further study the projection of a fragment and its initial velocity once the rupture occurs. Indeed, in the case of the axisymmetric elements, the deletion of the failed element would lead to the creation of a fragment, which is then projected.

\section{REFERENCES}

[1] Beltman, W., Burcsu, E., Shepherd, J., Zuhal, L., 1999, "The structural response of cylindrical shells to internal shock loading", J. Pressure Vessel Technology, 121, pp. 315-322

[2] Daudonnet, B., Woznica, K., Mercier, F., Klosowski, P., 2005, "Modeling of damage in a circular plate subjected to dynamic excitation", $8^{\text {th }}$ Conference Shell Structured Theory and Application, Gdansk-Jurata

[3] Daudonnet, B., 2006, «Etude numérique de la rupture d'éléments de structures constituant des réservoirs sous chargement dynamique », Ph.D. Thesis of Université d'Orléans

[4] Emery, A.F., Kobayashi, A.S., Love W.J., Place, B.W., Lee C., Chao, Y.H., 1986, "An experimental and analytical investigation of axial crack propagation in long pipes", Eng. Frac. Mech., 23 (1), pp. 215-226

[5] Florence, A.L., 1966, "Circular plate under a uniformly distributed impulse", Int. J. Solids Struct., 2, pp. 37-47

[6] Fthenakis, V.M., Rohatgi, U.S., Chung, B.D., 2003, "A simple model for predicting the release of a liquid-vapor mixture from a large break in a pressurized container", J. Loss Prev. Process Ind., 16 (1), pp. 61-72

[7] Haque, A., Richardson, S., Savillle, G., Chamberlain, G., 1990, "Rapid depressurization of pressure vessels", J. Loss Prev. Process Ind., 3 (1), pp. 4-7

[8] Iung, T., 1994, «Propagation rapide et arrêt des fissures dans les aciers pour gazoducs. Rupture par clivage et rupture ductile », Ph.D. Thesis of l'Ecole Nationale Supérieure des Mines de Paris

[9] Johnson, G.R., Cook, W.H., 1985, "Fracture characteristics of three metals subjected to various strains, strain rates, temperatures and pressures", Eng. Frac. Mech., 21, pp.3148

[10]Lee, Y-W, Wierzbicki, T., 2005, "Fracture prediction of thin plates under localized impulsive loading. Part II : discing and petalling", Int. J. of Impact and Eng., 31, pp. 1277-1308

[11]Lemaitre, J., Chaboche, J.-L., 1998, « Mécanique des matériaux solides », Dunod

[12]Leung, J.C., 1990, "Two-phase flow discharge in nozzles and pipes - a unified approach", J. Loss Prev.Process Ind., 3 (1), pp. 27-32

[13]MSC Software, MSC.MARC/MSC.MENTAT, Version 2005 
[14] Nurick, G.N., Martin, J.B., 1989, "Deformation of thin plates subjected to impulsive loading - a review - Part II: Experimental studies", Int. J. Impact Eng, 8 (2), pp. 171186

[15]Nurick, G.N., Pearce, H.T., Martin J.B., 1986 "The deformation of thin plates subjected to impulsive loading, In Inelastic Behaviour of Plates and Shells", (Ed. L. Bevilacqua). Springer-Verlag, Berlin

[16] Pennetier, O., Renard, J., 1998, « Structures minces face à une explosion, application à la gestion de risques industriels », Mécanique Industrielle et Matériaux 51 (2), pp. 67-69

[17]Qiu, H., Enoki, M., Kawaguchi, Y., Kishi, T., 2003, A model for the dynamic fracture toughness of ductile structural steel. Eng. Frac. Mech., 70 (5), pp. 589-598

[18]Recho, N., 1995, « Rupture par fissuration des structures », Hermès

[19] Rivalin, F., 1998, « Développement d'aciers pour gazoducs à haute limite d'élasticité et ténacité élevée: mécanique et mécanismes de la rupture ductile à grande vitesse », Ph.D Thesis of the Ecole Nationale Superieure des Mines de Paris

[20]Rivalin, F., Besson, J., Pineau, A., Di Fant, M., 2001, "Ductile tearing of pipeline-steel wide plates II. Modeling of in-plane crack propagation", Eng. Fract. Mech., 68, pp. 347-364

[21] Su, B., Bhuyan, G.S., 1999, "Elastic fracture properties of all-steel gas cylinders with different axial crack types", Int. J. Press. Vessels and Piping., 76 (1), pp. 23-33

[22] Teeling-Smith, R.G., Nurick, G.N., 1991, "The deformation and tearing of thin circular plates subjected to impulsive loads", Int. J. Impact Engng, 11 (1), pp. 77-91

[23] Woodward, J.L., Mudan, K.S., 1991, "Liquid and gas discharge rates through holes in process vessels", J. Loss Prev. Process Ind., 4 (3), pp. 161-165

[24] Woznica, K., Pennetier, O., Renard, J., 2001, "Experiments and numerical simulation on thin metallic plates subjected to an explosion", J. Eng. Mater. Technol., 123, pp. 203-209 